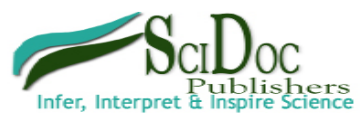

\author{
International Journal of Diabetology \& Vascular Disease Research(JjDVR) \\ ISSN 2328-353X
}

\title{
Treatment of Hypercholesterolemia in Patients with Diabetes Mellitus
}

Aronow WS

Research Article

Professor of Medicine, New York Medical College/Westchester Medical Center, Valhalla, NY, USA.

Abstract
Numerous studies have shown that statins reduce cardiovascular events including stroke and mortality in diabetics. The American Diabetes
Association 2013 guidelines recommend that diabetics at high risk for cardiovascular events should have their serum low-density lipopro-
tein (LDL) cholesterol reduced to $<70 \mathrm{mg} / \mathrm{dL}$ with statins. Lower-risk diabetics should have their serum LDL cholesterol reduced to $<$
$100 \mathrm{mg} / \mathrm{dL}$. The 2013 American College of Cardiology/American Heart Association lipid guidelines recommend giving high-dose statins
to adult diabetics aged $\leq 75$ years with atherosclerotic vascular disease (ASCVD) unless contraindicated with a class I indication and
moderate-dose or high-dose statins to diabetics with ASCVD $\geq 75$ years with a class IIa indication. Diabetics $\geq 21$ years with a serum
LDL cholesterol of $\geq 190 \mathrm{mg} / \mathrm{dL}$ should be treated with high-dose statins with a class I indication. For primary prevention in diabetics
aged 40 to 75 years and serum LDL cholesterol between 70 to $189 \mathrm{mg} / \mathrm{dL}$, moderate-dose statins should be given with a class I indica-
tion. For primary prevention in diabetics aged 40 to 75 years, a serum LDL cholesterol between 70 to $189 \mathrm{mg} / \mathrm{dL}$, and a 10 -year risk of
ASCVD of $\geq 7.5 \%$ calculated from the Pooled Heart Equation, high-dose statins should be given with a class IIa indication. For primary
prevention in diabetics aged 21 to 39 years or older than 75 years and a serum LDL cholesterol between 70 to 189 mg/dL, moderate-dose
statins or high-dose statins should be given with a class IIa indication. There is no additional ASCVD reduction from adding nonstatin
therapy to further lower non-high-density lipoprotein (HDL) cholesterol once an LDL cholesterol goal has been reached. Clinical tri-
als have found no lowering of cardiovascular events or mortality in diabetics treated with statins by addition of nicotinic acid, fibric acid
derivatives, ezetemibe, or drugs that raise serum HDL cholesterol.

*Corresponding Author:

Wilbert S. Aronow,

Cardiology Division, New York Medical College, Macy Pavilion, Room 138, Valhalla, NY, USA.

Tel: (914) 493-5311; Fax: (914)-235-6274

E-mail: wsaronow@aol.com

Received: March 17,2014

Accepted: April 07, 2014

Published: April 09, 2014

Citation: Aronow WS (2014) Treatment of Hypercholesterolemia in Patients with Diabetes Mellitus. Int J Diabetol Vasc Dis Res. 2(3), 54-56. doi: http://dx.doi.org/10.19070/2328-353X-1400010

Copyright: Aronow WS ${ }^{\odot} 2014$ This is an open-access article distributed under the terms of the Creative Commons Attribution License, which permits unrestricted use, distribution and reproduction in any medium, provided the original author and source are credited.

\section{Introduction}

Numerous studies have demonstrated that statins reduce cardiovascular events including stroke and mortality in diabetics $[1,8]$. At 5-year follow-up of 5,963 diabetics aged 40 to 80 years in the Heart Protection Study randomized to simvastatin $40 \mathrm{mg}$ daily or to double-blind placebo, simvastatin reduced first major vascular event (coronary event, stroke, or revascularization) 22\% from $25.1 \%$ to $20.2 \%$ compared with placebo $(p<0.0001)$ [1]. Of the 2,912 diabetics without occlusive arterial disease at study entry, simvastatin reduced first major vascular event by $33 \%(p=0.0003)$ [1]. Of the 2, 426 diabetics with a serum LDL cholesterol below $116 \mathrm{mg} / \mathrm{dL}$ at study entry, simvastatin reduced first major vascular event by $27 \%(p=0.0007)$ [1]. Treatment of diabetics without occlusive arterial disease for 5 years reduced 1 major vascular event in 45 patients per 1,000 treated and prevented 70 first or subsequent major vascular events per 1,000 patients treated [1].
At 5.4-year median follow-up of 202 diabetics with coronary artery disease and hypercholesterolemia in the Scandinavian Simvastatin Survival Study, compared with double-blind placebo, diabetics randomized to simvastatin 20 to $40 \mathrm{mg}$ daily had a $43 \%$ reduction in all-cause mortality $(p=0.087)$, a $55 \%$ reduction in major coronary events $(\mathrm{p}=0.002)$, and a $37 \%$ reduction in any atherosclerotic event $(p=0.018)$ [2]. At 5-year follow-up of 586 diabetics with coronary artery diseases and a mean serum total cholesterol level of $209 \mathrm{mg} / \mathrm{dL}$ in the Cholesterol and Recurrent Events trial, compared with double-blind placebo, pravastatin 40 $\mathrm{mg}$ daily decreased the incidence of fatal coronary events or nonfatal myocardial infarction $25 \%$ from $37 \%$ to $29 \%$ (p $=0.05$ ) [3].

In the Collaborative Atorvastatin Diabetes Study, 2, 838 diabetics with no cardiovascular disease and a serum LDL cholesterol less than $160 \mathrm{mg} / \mathrm{dL}$ were randomized to atorvastatin $10 \mathrm{mg}$ daily or to double-blind placebo [4]. At 3.9-year median follow-up, compared with placebo, atorvastatin significantly reduced time to first occurrence of acute coronary events, coronary revascularization, or stroke by $37 \%(\mathrm{p}=0.001)$, acute coronary events by $36 \%(9 \%$ to $55 \%$ ), stroke by $48 \%$ (11\% to $69 \%$ ), and all-cause mortality by $27 \%(\mathrm{p}=0.059)[4]$.

In an observational prospective study of 171 men and 358 women, mean age 79 years, with prior myocardial infarction, diabetes mellitus, and a serum low-density lipoprotein (LDL) cholesterol of $125 \mathrm{mg} / \mathrm{dL}$ or higher, 279 of 529 diabetics (53\%) were treated with statins [5]. At 29-month follow-up, compared with no treatment with statins, use of statins significantly decreased in elderly persons coronary heart disease death or nonfatal myocardial infarction by $37 \%$ and stroke by $47 \%$ [5]. The greater the reduction in serum LDL cholesterol, the greater the reduction in new coronary events [6] and in stroke [7].

A meta-analysis was performed of 14 randomized trials of statins used to treat 18, 686 diabetics (1,466 with type 1 diabetes and 
17,220 with type 2 diabetes) [8]. Mean follow-up was 4.3 years. All-cause mortality was reduced $9 \%$ per $\mathrm{mmol} / \mathrm{L}$ reduction in serum LDL cholesterol ( $\mathrm{p}=0.02$ ). Major cardiovascular events were reduced $21 \%$ per $\mathrm{mmol} / \mathrm{L}$ reduction in serum LDL cholesterol, $\mathrm{p}<0.0001$. Statins caused in diabetics a $22 \%$ reduction in myocardial infarction or coronary death $(p<0.0001)$, a $25 \%$ reduction in coronary revascularization $(p<0.0001)$, and a $21 \%$ reduction in stroke $(p=0.0002)$. After 5 years, 42 fewer diabetics per 1,000 diabetics treated with statins had major cardiovascular events [8].

In the Fenofibrate Intervention and Event Lowering in Diabetes (FIELD) study, 9,795 type 2 diabetics (2,131 with cardiovascular disease) were randomized to fenofibrate or double-blind placebo [9]. Mean follow-up was 5.0 years. The primary outcome of coronary events was not significantly reduced by fenofibrate. Fenofibrate insignificantly increased coronary heart disease mortality by $19 \%[9]$.

In the Action to Control Cardiovascular Risk in Diabetes (ACCORD) trial, 5,518 type 2 diabetics at high risk for cardiovascular disease were randomized to simvastatin plus fenofibrate or to simvastatin plus double-blind placebo [10]. Mean follow-up was 4.7 years. Compared with simvastatin plus placebo, simvastatin plus fenofibrate did not lower the incidence of fatal cardiovascular events, nonfatal myocardial infarction, or nonfatal stroke [10]. Among 3,414 patients with atherosclerotic cardiovascular disease and low serum high-density lipoprotein (HDL) cholesterol levels treated with simvastatin plus ezetimibe if needed to maintain the serum LDL cholesterol less than $70 \mathrm{mg} / \mathrm{dl}$, at 36-month followup, patients randomized to niacin had improvements in serum HDL cholesterol and triglyceride levels but no clinical improvement compared to patients randomized to placebo [11].

At the American College of Cardiology Meeting on March 9, 2013, Dr. Jane Armitage presented results from the Heart Protection study 2-Treatment of HDL to Reduce the Incidence of Vascular Events (HPS2-THRIVE) study. In this study, 25, 673 high-risk patients were randomized to treatment with simvastatin or simvastatin/ezetimibe plus extended-release niacin plus the anti-flushing agent laropriprant or to treatment with simvastatin or simvastatin/ezetimibe. At 3.9-year follow-up, compared to treatment with simvastatin or simvastatin/ezetimibe, addition of niacin did not decrease the primary outcome of major vascular events but increased 31 serious adverse events per 1,000 niacintreated patients. Excess diabetic complications were increased $3.7 \%(\mathrm{p}<0.0001)$. Excess new diabetes was increased $1.8 \%$ $(p<0.0001)$. Excess infection was increased 1.4\% ( $p<0.0001)$. Excess gastrointestinal complications were increased $1 \%(\mathrm{p}<0.0001)$. Excess bleeding (gastrointestinal and intracranial) was increased $0.7 \%(\mathrm{p}<0.0002)$.

The American Diabetes Association 2013 guidelines recommend that diabetics at high risk for cardiovascular events should have their serum LDL cholesterol reduced to less than $70 \mathrm{mg} / \mathrm{dL}$ with statins [12]. Lower-risk diabetics should have their serum LDL cholesterol reduced to less than $100 \mathrm{mg} / \mathrm{dL}$ [12]. Combination therapy of a statin with either a fibrate or niacin has not been found to provide additional cardiovascular benefit above statin therapy alone and is not recommended [12]. Hypertriglyceridemia should be treated with dietary and lifestyle changes [12]. Severe hypertriglyceridemia should be treated with drug therapy to decrease the risk of acute pancreatitis [12].
The 2013 American College of Cardiology/American Heart Association lipid guidelines recommend the use of high-dose statins (rosuvastatin 20 to $40 \mathrm{mg}$ daily or atorvastatin 40 to $80 \mathrm{mg}$ daily) to adults aged 75 years and younger with atherosclerotic vascular disease (ASCVD) with or without diabetes mellitus unless contraindicated with a class I indication [13]. Moderate-dose or highdose statins are reasonable to administer to patients with ASCVD with or without diabetes mellitus older than 75 years with a class IIa indication. Persons aged 21 years and older with a serum LDL cholesterol of $190 \mathrm{mg} / \mathrm{dL}$ or higher with or without diabetes mellitus should be treated with high-dose statins with a class I indication. For primary prevention in diabetics aged 40 to 75 years and a serum LDL cholesterol between 70 to $189 \mathrm{mg} / \mathrm{dl}$, moderate-dose statins should be given with a class I indication. For primary prevention in diabetics aged 40 to 75 years, a serum LDL cholesterol between 70 to $189 \mathrm{mg} / \mathrm{dL}$, and a 10-year risk of ASCVD of 7.5\% or higher calculated from the Pooled Heart Equation, high-dose statins should be administered with a class IIa indication. For primary prevention in diabetics aged 21 to 39 years or older than 75 years and a serum LDL cholesterol between 70 to $189 \mathrm{mg} /$ dL, moderate-dose statins or high-dose statins should be given with a class IIa indication. These guidelines also state that there is no additional ASCVD reduction from adding nonstatin therapy to further lower non-HDL cholesterol once an LDL cholesterol goal has been reached. Clinical trials have demonstrated no lowering of cardiovascular events or mortality in persons treated with statins by addition of nicotinic acid, fibric acid derivatives, ezetemibe, or drugs that raise HDL cholesterol [13].

\section{References}

[1]. Collins R, Armitage J, Parish S, et al. MRC/BHF Heart Protection Study of cholesterol-lowering with simvastain in 5963 patients with diabetes: a randomised placebo-controlled trial. Lancet 2003; 361: 2005-2016.

[2]. Pyorala K, Pedersen TR, Kjekshus J, et al. Cholesterol lowering with simvastatin improves prognosis of diabetic patients with coronary heart disease, A subgroup analysis of the Scandinavian Simvastatin Survival Study (4S). Diabetes Care 1997; 20: 614-620.

[3]. Sacks FM, Pfeffer MA, Moye LA, et al. The effect of pravastatin on coronary events after myocardial infarction in patients with average cholesterol levels. N Engl J Med 1996;335:1001-1009.

[4]. Calhoun HM, Betteridge DJ, Durrington PN, et al. Primary prevention of cardiovascular disease with atorvastatin in type 2 diabetes mellitus in the Collaborative Atorvastatin Diabetes Study (CARDS): multicentre randomized placebo-controlled trial. Lancet 2004; 364: 685-696.

[5]. Aronow WS, Ahn C, Gutstein H. Reduction of new coronary events and of new atherothrombotic brain infarction in older persons with diabetes mellitus, prior myocardial infarction, and serum low-density lipoprotein cholesterol $\geq 125 \mathrm{mg} / \mathrm{dL}$ treated with statins. J Gerontol: Med Sci 2002;57A:M747-M750.

[6]. Aronow WS, Ahn C. Incidence of new coronary events in older persons with prior myocardial infarction and serum low-density lipoprotein cholesterol $\geq 125 \mathrm{mg} / \mathrm{dL}$ treated with statins versus no lipid-lowering drug. Am J Cardiol 2002;89:67-69.

[7]. Aronow WS, Ahn C, Gutstein H. Incidence of new atherothrombotic brain infarction in older persons with prior myocardial infarction and serum lowdensity lipoprotein cholesterol $\geq 125 \mathrm{mg} / \mathrm{dL}$ treated with statins versus no lipid-lowering drug. J Gerontol: Med Sci 2002;57A:M333-M335

[8]. Cholesterol Treatment Trialists' (CTT) Collaborators, Kearney PM, Blackwell L, et al. Efficacy of cholesterol-lowerring therapy in 18,686 people with diabetes in 14 randomised trials of statins: a meta-analysis. Lancet 2008; 371: 117-125.

[9]. Keech A, Simes RJ, Barter P, et al. Effects of long-term fenofibrate therapy on cardiovascular events in 9,795 people with type 2 diabetes mellitus (the FIELD study): randomised controlled trial. Lancet 2005; 366: 1849-1861.

[10]. The ACCORD Study Group. Effects of combination lipid therapy in type 2 diabetes mellitus. N Eng J Med 2010; 362: 1563-1574.

[11]. AIM-HIGH Investigators, Boden WE, Probstfield JL, et al. Niacin in patients with low HDL cholesterol levels receiving intensive statin therapy. N Engl J Med 2011; 365: 2255-2267.

[12]. American Diabetes Association.. Standards of medical care in diabetes--2013. Diabetes Care 2013; 36 (supplement 1): S11-S66. 
[13]. Stone NJ, Robinson J, Lichtenstein AH, et al. 2013 ACC/AHA guideline on the treatment of blood cholesterol to reduce atherosclerotic cardiovascular risk in adults: a report of the American College of Cardiology/American
Heart Association Task Force on Practice Guidelines. J Am Coll Cardiol 2013; Nov 7 published online ahead of print PMID: 24239923 